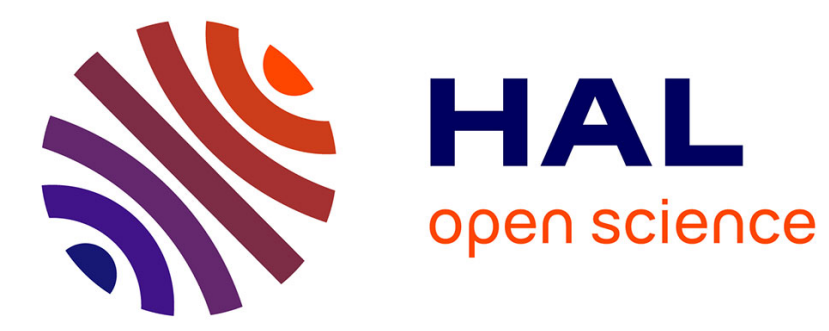

\title{
Copper vapor laser place in the laser isotope separation program
}

Patrick Lemaire, J. Maury

\section{To cite this version:}

Patrick Lemaire, J. Maury. Copper vapor laser place in the laser isotope separation program. Journal de Physique IV Proceedings, 1994, 04 (C4), pp.C4-635-C4-638. 10.1051/jp4:19944169 . jpa-00252626

\section{HAL Id: jpa-00252626 https://hal.science/jpa-00252626}

Submitted on 1 Jan 1994

HAL is a multi-disciplinary open access archive for the deposit and dissemination of scientific research documents, whether they are published or not. The documents may come from teaching and research institutions in France or abroad, or from public or private research centers.
L'archive ouverte pluridisciplinaire HAL, est destinée au dépôt et à la diffusion de documents scientifiques de niveau recherche, publiés ou non, émanant des établissements d'enseignement et de recherche français ou étrangers, des laboratoires publics ou privés. 


\title{
Copper vapor laser place in the laser isotope separation program
}

\author{
P. LEMAIRE and J. MAURY
}

Commissariat à l'Energie Atomique, CEA VALRHO, Département des Technologies de l'Enrichissement (DTE), Service Laser et Chimie (SLC), BP. 111, 26702 Pierrelatte cedex, France

\begin{abstract}
:
The French uranium enrichment program, SILVA ( Séparation Isotopique par Laser de la Vapeur Atomique d'uranium), has chosen yet the Copper Vapor Laser (CVL) for dye laser pumping. CVL is the most efficient laser in the visible, for pulsed operation, and with a high repetition rate. Over $400 \mathrm{~W}$ of average optical power is achived from one unit; work is done under CEA/CILAS contract. A $120 \mathrm{~W}$ laser, the ICL 100 is available on the market from CEA/CILAS. MTBF over $1000 \mathrm{~h}$ is specified. In MOPA (Master oscillator power amplifier) configuration, hundred of hours at nearly $600 \mathrm{~W}$ level is obtained in the CEA facilities. Other CVL industrial applications like hole drilling or paint removing are considered.
\end{abstract}

\section{Introduction}

Copper vapor laser developement is carried out in close coupling with its main application: SILVA.

This new process should complete and then replace the gazeous diffusion in the early 2010's. The actual production plant EURODIF will stopped as some other plants in USA, and, the worldwide needs are planed to increase like energy requirements.

Preliminar analyses show that SILVA will have a low exploitation cost . Investment will decrease as the technology will be handled. Choosing AVLIS derives from many other reasons like process selectivity, compactness, modularity, introduction of new technologies...

SILVA process rests on the difference in the excitation energy between isotopes of an element. Energy is brought by perfectly tuned dye lasers. By a multistep photoexcitation up to the ionization threshold ( $6.2 \mathrm{ev}$ is reach in 3 steps for visible light), the chosen isotope is selectively ionized, and extracted by an electric field (An other step is added for metastable depletion).

SILVA facilities include, on one hand, high power pulsed - more than $20 \mathrm{kHz}$ - dye lasers, and the associed pumping laser, the CVL. On the other hand, the laser irradiated uranium vapor is obtained from electron beam heating. Metallic uranium is used.

A CEA's complete representative pilot has shown the feasibility.

The topic of this work is to present CEA Copper Vapor Laser improvment in power, efficiency, reliability, and physics understanding. The last chapter is devoted to some other applications of the CVL. 


\section{CEA's Pumping laser State of Art for SILVA}

\section{CVL}

Up to 1989 , only modules of $30 \mathrm{~W}$ of optical mean power each, were home made. Similar powers are available on the market. In the early 1993's, CEA associated with CILAS put on the market a very reliable unit, the ICL 100 which gives optical power up to $120 \mathrm{~W}$ specified, with over 1000 hours MTBF.

From that time CEA/CILAS R\&D permits us to reach optical power above $400 \mathrm{~W}$ from an module - Measurement is made in an oscillator configuration (infinity $/ / \approx 30 \mathrm{~m}$; curvature mirrors) -. The latter performance was obtained with thyratron triggers. In parallel, an all "solid state" power supply was developed. Running time exceeds more than 3,000. hours on the first small unit, the MTBF is not yet quantified.

In MOPA configuration, a $600 \mathrm{~W}$ of optical power was achieved a year ago. An objective of 1.5 to $2 \mathrm{~kW}$ of optical power per chain is under consideration for SILVA application plant.

\section{Nd:YAG}

The CVL's rival is the "2nd Harmonic of the Tranversely Diode pumped, Q Swiched, Nd:YAG laser". Up to 1992, less than one watt was achieved at a rate of $100 \mathrm{~Hz}$ in the CEA [1]. More recently, over $5 \mathrm{~W}$ performance, was obtained at higher repetition rate (rate up to $20 \mathrm{kHz}$ ) [2] . At all stages of the laser, losses and heat removal is the main difficulty. But progress are very sharp.

CVL survey should come from improvment of:

- absolute mean power (per pulse or repetition rate),

- efficiency (power supply and laser medium)

- and reliability (throught solid state power supply component standardization ).

\section{Copper Vapor Laser physics review [3]}

SILVA's CVL is a longitudinal discharge laser pulsed at a rate of $5.000 \mathrm{~Hz}$. It emits 2 lasing lines at $511 \mathrm{~nm}$ and $578 \mathrm{~nm}$, both with hyperfine structure[4]. The active medium, bordered by an alumina tube, is a mixture $(\approx 100: 1)$ of neon and copper. The latter is coming from the saturated pressure of copper metal heated at $\approx 1500^{\circ} \mathrm{C}$. Neon pressure is optimized depending on the tube bore radius and the inner electric field (E) from 20 to 100 mbar[5].

Current over several thousand ampere, depending on the tube bore radius and the $\mathbf{E}$ field, goes through the active medium. For inductance lowering, current should return along the external tube because the laser gain is higher when the current time derivative is greater. Therefore, power extrapolation through volume extrapolation should go to bore radius increase. Usualy limitation occurs during diameter extrapolation from an overheated central zone [6]. Consequently, for high efficiency in large bore CVL: 
- The temperature in the central zone should be reduced [7, for example]

- Time variation of the excitation should be as swift as possible

- The lasing medium should be as clean [8] \&homogeneous in species and temperature as possible.

For the $400 \mathrm{~W}$ performance, the ratio optical power to deposited power is 1.7 . For the ICL 100 the wall plug efficiency is 0.8 . Both were measured under oscillator configuration.

Strong relationship connects optical power or gain to electron energy and to the applied electric field. Experimental investigation, and modelisation was undertaken about all those parameters:

On the energy carriers, the electrons

- a routine space \&time resolved electrons density diagnostic is developed [9].

- a space \&time resolved electron energy distribution function is under development

On the laser gain

- a space \&time resolved lower level density diagnostic was developed [10].

On the Electric field $\mathbf{E}$

- a space\&time resolved $\mathbf{E}$ diagnostic is under development for discharge and electrode sheath

On electron transport coefficient

- Actions means are studied

\section{Copper Vapor Laser technology improvment}

Electrical power is supplied from the circuit simplified and schematized on the figure.

The main effort is done on reliability.

"All solid state" power supplies are developped. Multi-thyratron trigger is replaced by a set of low voltage thyristors in parallel, like IGBTs, followed by a low leakage and low impedance voltage transformer [11]. A multistage magnetic pulse compressor for electric pulse narrowing is unavoidable. Modifications take place before the peaking

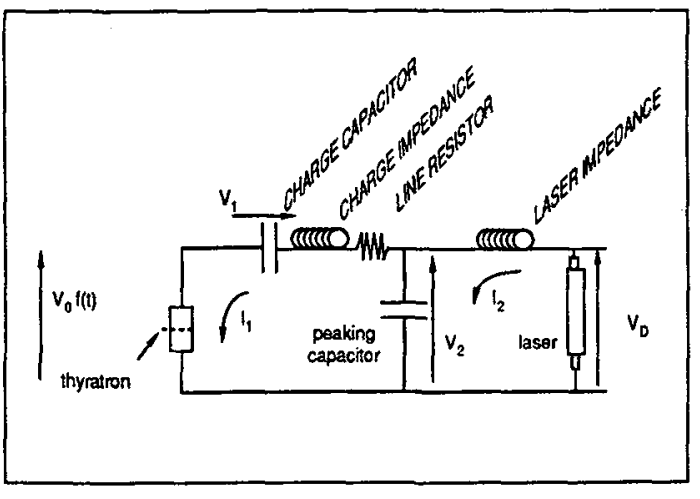
capacitor. The second way is a set of serie-parallel high voltage MOS transistors [12].

\section{Other applications}

The high average power of the CVLs makes them useful for a lot of applications from the huge one like, artificial star... [13], to the industrial one:

- Drilling holes in copper, aluminium, or alumina with any gas assistance (Unpublished). 
Only few watts are useful to drill a hole in a $0.5 \mathrm{~mm}$ thick copper plate for less than $0.2 \mathrm{~s}$. Hardening measurements are also done in the vicinity of the holes. They show an increase from 70 to $85 \mathrm{Hv}$ (Vickers).

- Paints removal is efficient.

The peak power make CVLs attractive for dye laser pumping, frequency doubling, frequency adding[14], or ultra short pulse generation...

Fiber optic power transportation is studied. Single fiber can deliver more than $100 \mathrm{~W}$.

\section{Conclusion}

Since 1985 CVL has been developed in the CEA with CILAS. 100W was reached in 1989. More than $400 \mathrm{~W}$ is obtained now with the assurance to go beyond after optimization. Reliability of high power laser is under considerations with a qualified solid state power supply involving IGBT triggers.

A industrial version available from 1993, the ICL 100, is able to warrant $120 \mathrm{~W}$ during $1000 \mathrm{~h}$ (MTBF). Average \& peak power make them useful in many other applications than SILVA where the visible wavelength is necessary, or when optical fiber transportation could not be avoid.

\section{References}

[1] B. Le Garrec, Ph. Féru "Laser Nd:YAG pompé transversalement par diodes lasers" OPTO 92 Paris 14-16 april 1992, ESI publications P.433-437.

[2] (B. Le Garrec : Private communication)

[3] For ex.: Hecht "Back to basis: Metal vapor laser" Laser Focus World p99 Oct. 1993

[4] Tenenbaum et al. Optics Com. Vol.32, N³, p473 1980

[5] J.J. Chang "Pressure dependence of copper laser output characteristics" Applied Optics Vol.32,N²7, 20Sept.1993.

[6] M.J. Kushner, B.Warner "Large bore CVL kinetics and scaling issues"J. Applied Phys. 54, (6) June 83

[7] M.A.Lane " High power copper vapor laser head" E\&TR p 21-28 May 93

[8] Gabay et al."Stabilization of high power CVL" Opt. and Quant. Elect. 23, (1991)

[9] Le Guyadec, Chamouard, Goossens, Gilbert, Lemaire "Radial and time resolved measurement of electron density in a CVL" Opt. Com. 100 (1993)

[10] Chamouard ; Thèse n²582 Université Paris sud ORSAY 17/2/93

[11] Chatroux, Maury, Hennevin"IGBT: asolid state switch" Proc. EO Laser 93 Los.Ang.

[12] Guidini, Chatroux, Guyon"Semi conductor power MOSFETs devices in series" Proc. EPE Brighton (GB) sept 93

[13] Bass et al."High average power dye laser at L.L.N.L" Applied optic 31 n³3 20/11/92

[14] Naylor et al. POSTER VP 58 Laser M2P 93 